\title{
Consenso en adopción internacional. Extracto de la Guía CORA para pediatras y otros profesionales sanitarios
}

\author{
Grupo de desarrollo de la Guía CORA,
} Consenso en adopción internacionala, . España.

\author{
Rev Pediatr Aten Primaria. 2009; I I (Supl I 7):s339-s348 \\ Maite de Aranzábal Agudo, mdearanzabal@gmail.com
}

\begin{abstract}
Resumen
La adopción internacional (Al) es un fenómeno social en auge en nuestro medio. Todos los niños procedentes de Al tienen el antecedente de haber estado expuestos a múltiples factores de riesgo para la salud. Es por ello que CORA (Coordinadora de Asociaciones en Defensa de la Adopción y el Acogimiento) reunió a un grupo de profesionales que elaboró una guía consensuada para establecer de manera protocolizada la consulta médica preadoptiva, la evaluación inicial y el seguimiento de los niños adoptados en el extranjero. En este texto se presenta un extracto de dicha guía.
\end{abstract}

Palabras clave: Adopción internacional.

\section{Abstract}

International adoption (IA) is a social phenomenon on the rise in our country. All children from IA have a history of being exposed to multiple health risk factors. That is why CORA (Coordination Association in Defence of the Adoption and the Fostering) assembled a group of professionals who developed a consensual guide to establish a protocol of pre-adoption medical consultation, initial assessment and monitoring of children adopted abroad. This text is an excerpt from the guide.

Key words: International adoption.

\section{Introducción}

La adopción internacional (Al) ha au- mentado en nuestro entorno de forma extraordinaria. Todos los niños proce-

\footnotetext{
a (Por orden alfabético) Susana Alberola López (pediatra, Palencia), Ana Berástegui Pedro-Viejo (psicóloga, Madrid), Maite de Aranzábal Agudo (pediatra, Vitoria), Ángel Cortés Lozano (pediatra, Madrid), Victoria Fumadó Pérez (pediatra, Barcelona), Milagros García LópezHortelano (pediatra, Madrid), Jesús García Pérez (pediatra, Madrid), Ángel Hernández Merino (pediatra, Alcorcón, Madrid), Julián Lirio Casero (pediatra, Madrid), Alberto Núñez López (coordinación general, Alcalá de Henares, Madrid), Gonzalo Oliván Gonzalvo (pediatra, Zaragoza), Lila Parrondo Creste (psicóloga, Madrid).

b El texto que se presenta corresponde a un extracto de la obra Consenso en adopción internacional. Guía breve para pediatras y otros profesionales sanitarios, 2008. Valladolid: CORA; 2008, realizado por Maite de Aranzábal Agudo y aprobado por el grupo de autores.
} 
dentes de Al tienen el antecedente de haber estado expuestos a potenciales factores de riesgo sociosanitario tanto por la pobreza económica como por procesos infecciosos, genéticos o ambientales, perinatales o de deprivación afectiva o de negligencia continuada. Es por ello que CORA (Coordinadora de Asociaciones en Defensa de la Adopción y el Acogimiento) reunió a un grupo de profesionales que trabajan con estos niños y elaboró una guía consensuada para establecer de manera protocolizada la consulta médica preadoptiva, la evaluación inicial y el seguimiento de los adoptados en el extranjero. En este texto se presenta un extracto de dicha guía ${ }^{1-3}$.

\section{Factores de riesgo y problemas de salud en la Al}

Obviamente estos niños tienen más factores de riesgo de salud, tanto psicológicos como físicos, debido a la pobreza, la falta de higiene, los cuidados alimentarios, preventivos y médicos, y las enfermedades endémicas de sus países o carencia afectiva sin posibilidad, en general, de crear un vínculo o referencia.

En las tablas I, II y III se pueden ver los problemas de salud más frecuentes

Tabla I. Problemas de salud muy frecuentes (> 25\%)

- Crecimiento físico (talla/edad inferior a -2 $\mathrm{DE}$, puntuación Z).

- Inmunizaciones ausentes, incompletas o que no crearon títulos de anticuerpos protectores.

- Ferropenia con o sin anemia.

- Problemas dermatológicos leves.

- Problemas adaptativos de la alimentación y del sueño.

- Parasitosis intestinal con o sin síntomas digestivos.

- Infecciones propias del niño (aparato respiratorio, digestivo, $\mathrm{ORL}$ ).

DE: desviación estándar; ORL: otorrinolaringología.

Tabla II. Problemas de salud frecuentes (5-25\%)

- Retraso de desarrollo psicomotor leve.

- Crecimiento físico (talla/edad entre -2 y -3 DE).

- Estado nutricional (peso/edad, peso/talla, IMC entre -2 y $-3 \mathrm{DE}$ ).

- Trastornos de conducta tipo impulsividad o atención dispersa.

- Problemas específicos del desarrollo madurativo:

- Adaptación social.

- Control esfinteriano.

- Adaptación escolar, etc.

- Lenguaje.

- Problemas bucodentales.

- Alteraciones oftalmológicas y ORL.

- Enfermedades infecciosas: infección tuberculosa latente.

- Eosinofilia.

- Inexactitud de la edad cronológica.

DE: desviación estándar; IMC: índice de masa corporal; ORL: otorrinolaringología. 
Tabla III. Problemas de salud menos frecuentes ( $<5 \%)$

- Infección por el virus de la hepatitis B (aguda, crónica o resuelta).

- Hemoglobinopatías.

- Alteraciones endocrinas:

- Disfunción tiroidea (generalmente hipotiroidismo subclínico).

- Variantes del desarrollo puberal (retraso puberal, pubertad temprana).

- Trastornos del crecimiento y nutrición graves:

- Talla/edad o índices ponderales menor de -3 DE.

- Raquitismo.

- Trastornos psicopatológicos graves:

- Trastornos de conducta.

- Síndrome de estrés postraumático.

- Trastornos de origen prenatal: hipoxia crónica, infección intrauterina, exposición al alcohol (trastornos del espectro alcohólico fetal, síndrome alcohólico fetal), exposición a drogas/fármacos.
- Enfermedades infecciosas adquiridas/ congénitas $(\approx 1 \%)$ :

- Tuberculosis activa.

- Sífilis.

- Paludismo.

- Enfermedad de Chagas.

- Otras enfermedades parasitarias.

- Poliomielitis, tos ferina, sarampión.

- Infección aguda por el virus de la hepatitis $\mathrm{A}$.

- Anticuerpos o infección por el virus de la inmunodeficiencia humana.

- Anticuerpos o infección por virus de la hepatitis $\mathrm{C}$.

- Toxoplasmosis, rubéola, citomegalovirus, herpes.

- Malformaciones congénitas (cardíacas, osteoarticulares, genitales, renales y vías urinarias, labio leporino-paladar hendido, etc.).

DE: desviación estándar.

sobre la base de la experiencia clínica obtenida en la evaluación de más de 6.000 niños adoptados por familias españolas en distintos países extranjeros.

Haciendo un breve resumen, el $90 \%$ de los problemas son leves y reversibles a corto o medio plazo, un $5 \%$ son reversibles a largo plazo, y otro $5 \%$ deja secuelas o son irreversibles.

En los últimos tres años estamos observando una mejora del nivel medio del estado de salud a la llegada de estos niños, hecho que sugiere que están recibiendo mejores cuidados durante su acogida en los domicilios o centros tutelares extranjeros.

\section{La consulta en preadopción:} ¿en qué consiste?

La visita preadoptiva es importante para:

- Orientar a la familia en base a los informes y documentación recibidos.

- Aconsejar sobre el viaje y posibles necesidades médico-preventivas del menor.

- Preparar la visita postadoptiva.

Debe quedar claro que el pediatra no es quien decide si el niño es "adopta- 
ble" o no, solo interpreta la documentación.

\section{La evaluación médica inicial}

Son atendidos en nuestro Sistema

Nacional de Salud de manera similar al resto de la población infantil. La Pediatría de Atención Primaria es un ámbito apropiado para la asistencia inicial de estos menores. Se realizará no más tar- de de los 15 días tras la llegada del niño, excepto si presenta enfermedad aguda.

¿Qué evaluar? Se realizará anamnesis de los antecedentes del menor a través de la recopilación de la información sociosanitaria que pueda aportar la familia de forma escrita u oral, así como una exploración física minuciosa y la realización de pruebas de cribado.

Tabla IV. Evaluación médica básica recomendada a todos los niños adoptados en el extranjero

- Exploración física completa.

- Evaluación del crecimiento y estado de nutrición.

- Evaluación inicial del desarrollo psicomotor.

- Evaluación de signos de maltrato.

- Evaluación del certificado oficial de inmunizaciones.

- Evaluación de la visión y audición.

- Pruebas de cribado de laboratorio:

- Hemograma.

- Hierro, transferrina y ferritina séricos.

- Bioquímica elemental.
- Cribado de raquitismo (fosfatasa alcalina, calcio, fósforo).

- Parásitos en heces (3 muestras).

- Serología VIH (anti-VIH 1 y 2) ${ }^{*}$,, .

- Serología hepatitis B (incluir los marcadores: $\mathrm{HBsAg}$, anti-HBs, anti- $\mathrm{HBc}$ IgG total) $\neq$, serología hepatitis $\mathrm{C}$ (anti-HCV) $\S_{1}^{* *}$.

- Serología sífilis (RPR y/o VDRL) †十.

- Prueba de tuberculina (técnica de Mantoux con 0,1 ml;

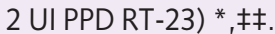

* Considerar la repetición a los 3-6 meses para descartar el período de incubación de un posible contagio anterior a la adopción no diagnosticado (para VIH, solo en casos con historia dudosa o procedentes de África subsahariana y que no haya realizado la prueba de PCR; para tuberculosis, en casos de Mantoux inicial negativo).

† VIH. Si la serología (ELISA) es positiva, se debe confirmar el diagnóstico: en menores de 18 meses, se realizarán dos pruebas de confirmación diagnóstica mediante técnica de PCR (reacción en cadena de la polimerasa); en mayores de 18 meses, se confirmará repitiendo anti-VIH-1 y VIH-2 (Western-Blot).

F $\quad$ Si la serología es positiva, determinar anti-HBC IgM, HBeAg, anti-HBe y anti-hepatitis Delta.

$\S$ Si serología positiva en niño mayor de 18 meses, confirmar diagnóstico determinando carga viral (VHC-RNA) por PCR

* Repetir a los 6 meses solo en caso de clínica sospechosa o duda.

†† Si pruebas reagínicas positivas confirmar con prueba treponémica específica (FTA-ABS IgG) y derivar. Esta prueba se realizará también en todos los menores de 1 año con confirmación o sospecha de que su madre tuvo sífilis.

f\# Realizar incluso en niños vacunados de BCG. La lectura debe realizarse a las 48-72 horas. Una induración mayor o igual a $10 \mathrm{~mm}$ se considera positiva (independientemente de que haya sido o no vacunado de $B C G$ ) e implica realizar estudio radiológico de tórax. Si la induración es menor de $10 \mathrm{~mm}$, se considera negativo. Habría que repetirlo a los 3-6 meses (ver apartado b) para evitar falsos negativos por inmunodepresión secundaria a desnutrición, infestación parasitaria, tratamiento con corticoides, infección por VIH, etc. Si el niño presenta clínica sugestiva de tuberculosis, sospecha epidemiológica, radiología de tórax patológica y/o está inmunodeprimido, una induración mayor o igual a $5 \mathrm{~mm}$ debe considerarse positiva. Cualquier niño con sospecha de enfermedad tuberculosa debe ser valorado en un centro especializado. 
Tabla V. Evaluación médica específica recomendada a algunos* niños adoptados en el extranjero

- Analizar criterios clínicos de sospecha de síndrome alcohólico fetal t.

- Evaluación de la dentición.

- Evaluación del desarrollo puberal.

- Evaluación de la edad cronológica.

- Pruebas de cribado de laboratorio:

- Estudio de hemoglobinopatías ¥.

- Talasemias, drepanocitosis, otras hemoglobinopatías.

- Glucosa-6-fosfato-deshidrogenasa.

- Bioquímica, sedimento de orina y cultivo.
- Coprocultivo § (1 muestra).

- Cribado endocrino-metabólico (hipotiroidismo, fenilcetonuria, etc.) **.

- Función tiroidea (T4 total, T4 libre, TSH) t十.

- Estudio de paludismo (gota gruesa y frotis de sangre periférica) $\neq \neq$.

- Investigación de citomegalovirus (cultivo de orina, IgM, IgG), toxoplasmosis y rubéola $(\operatorname{IgM}, \operatorname{lgG}) \neq \ddagger, \S \S$.

- Serología hepatitis A (IgM, IgG) キキ.

- Serología de enfermedad de Chagas (Tripanosoma Cruzi, IgG) ***.

* Según edad, país, informes médicos, niños con necesidades especiales, clínica y/o datos del examen inicial básico.

† Especialmente en procedentes de la Federación Rusa y Europa del este. Ver http://depts. washington.edu/ fasdpn/pdfs/guide2004.pdf y http://depts. washington.edu/fasdpn/

F Talasemias: China, India y sudeste Asiático; drepanocitosis: Caribe, África subsahariana, India,

Latino América; déficit de glucosa-6-fosfato deshidrogenada: África subsahariana).

$\S \quad$ Si sospecha clínica.

* En menores de 6 meses a los que no se les ha realizado cribado neonatal.

t† En mayores de 6 meses con retraso del desarrollo o con macrocefalia.

\#\# En casos con sospecha clínica.

$\S \S$ La investigación de citomegalovirus está indicada, aun en casos sin sospecha clínica, cuando la madre adoptante está embarazada.

* * Las áreas endémicas son Centroamérica y Sudamérica. Si la serología convencional es positiva, derivar.

Dentro de la evaluación medica inicial debemos diferenciar dos tipos de procedimientos: una evaluación básica e inicial para todos los niños (tabla IV) procedentes de Al y una específica para algunos niños (tabla V), en función de su edad, país de origen, informes médicos previos, signos o síntomas clínicos y/o datos del examen clínico-analítico inicial.

\section{Seguimiento}

Debido a que en un elevado porcentaje de los niños adoptados en el extranjero se detectan problemas en la evaluación médica, es recomendable realizar un seguimiento prolongado en el tiempo. Este seguimiento debería ser multidisciplinar y sistematizado, siendo coordinado por el pediatra responsable del menor (tabla VI).

\section{Crecimiento y estado de nutrición}

La malnutrición aparece en el 20\% de los adoptados internacionalmente. Su origen principal está en la situación socioeconómica, pudiendo ser agravada por otros elementos negativos.

Para conocer el estado de nutrición en la mayoría de los casos, incluso desde lactante, puede ser suficiente esta fór- 
Tabla VI. Seguimiento médico de los niños procedentes de Al

- Problemas de salud detectados en la evaluación médica inicial.

- Respuestas a los tratamientos administrados.

- Evolución longitudinal * de:

- Crecimiento y estado nutricional.

- Desarrollo psicomotor.

- Adecuada administración de inmunizaciones $t$.

- Adaptación de la alimentación.
- Evolución del desarrollo:

- Puberal $\neq$.

- Visión/audición.

- Dentición.

- Afectivo-emocional y comportamiento.

- Lenguaje.

- Social-escolar.

- Posible aparición de problemas de salud física y/o mental previamente no detectados o nuevos.

* Observando si se produce la recuperación esperada de los retrasos o trastornos existentes.

† En menores de 18 meses y mayores de esta edad sin certificado oficial o con certificado no fiable, se recomienda administrar todas las vacunas (calendario acelerado), con independencia de las que se hayan administrado en su país de origen. A todos los niños se les administrarán las vacunas pertinentes para adecuar sus inmunizaciones al calendario oficial vigente de la comunidad adoptiva o al recomendado por la Asociación Española de Pediatría.

F Especialmente en niñas adoptadas por encima de los 4 años de edad procedentes de India, sudeste de Asia y Latinoamérica (www.sepeap.es/libros/endocrino/Tanner.htm).

mula: Peso real x 100 / Peso de un niño normal para la misma talla. Según esta, si el déficit ponderal para la talla es del 10 al 15\% la malnutrición será leve; si lo es del 15 al $25 \%$, moderada, y si es mayor del $25 \%$, grave.

En caso de mala ganancia ponderal conviene recordar otros factores agravantes como la intolerancia a la lactosa de causa genética o adquirida, las infecciones intestinales crónicas o repetidas, la celiaquía o la alergia a proteínas de vacuno. Estas últimas enfermedades son a menudo silentes y solo en ocasiones son reconocidas por intolerancias, flatulencia o dolor abdominal. Debe realizarse la analítica pertinente $y$, además, solicitar proteínas totales, perfil tiroideo y marcadores de celiaquía.
La alimentación en los niños de adopción reciente -si no presentan una grave desnutrición- será equilibrada y sana, introduciendo paulatinamente los alimentos y con la fórmula o leche correspondiente a su edad. Si se trata de niños malnutridos es recomendable ir diversificando la dieta paulatinamente, prestando aún más atención a posibles intolerancias, prescribiendo un polivitamínico por algún tiempo.

Entre los problemas más comunes de hábitos alimenticios se encuentran la ingesta desproporcionadamente alta, y su contrario, el rechazo a la comida por la textura o diferencia con la anterior. En este caso hay que ir espesando la comida paulatinamente. Una vez descartadas todas las patologías, algunos niños siguen 
teniendo heces blandas, flatulencia o ansiedad por la comida durante meses.

Las secuelas de la malnutrición a largo plazo son mayores cuanto mayor haya sido el período de deprivación social o nutricional. Sin embargo, los estudios demuestran que tras 3 ó 4 años de tratamiento psicoafectivo y buena alimentación, la recuperación es total-física y mentalmente- si la adopción fue antes de los 6 meses, y casi total si fue antes de los 4 años.

\section{Crecimiento y gráficas}

Es importante seguir de cerca el crecimiento durante al menos 2 años con controles cada 6-12 meses, aunque la duración variará según casos individuales.

En el retraso de talla, siempre que mantengan un percentil de velocidad de crecimiento de 25 o más, una vez descartadas otras causas y siempre que la edad ósea sea acorde con la cronológica en más o menos 1 año (puede estar más retrasada en los casos de malnutrición o deprivación social), se sugiere esperar al menos 18 meses antes de enviar al endocrinólogo, ya que casi todos estos niños realizan el catch-up durante el primer año en el nuevo país.

Recomendamos el uso de las tablas de referencia de nuestra comunidad o país www.aepap.org/crecorbegozo.htm y www.aeped.es/protocolos/nutricion/9. pdf o las publicadas por la OMS (de momento solo para menores de 5 años) realizadas con una amplia muestra de niños de cada continente y disponibles en www.who.int/childgrowth/en/

\section{Seguimiento del desarrollo psicomotor}

Para evaluar el desarrollo psicomotor se recomienda el test de Denver (0-6 años) o el test Haizea-Llevant (0-5 años). Estas pruebas valoran el grado de desarrollo de las áreas manipulativa (motricidad fina), postural (motricidad gruesa), del lenguaje y psicosocial. Realizar una evaluación al llegar y otra a los 6 meses. Si se observa un gran retraso al llegar o si no se ha producido una mejoría en el área o áreas retrasadas -los problemas motores son los primeros en resolverse- o existe ansiedad parental muy llamativa, debe remitirse a un servicio de Atención Temprana.

En la mayoría de los casos el retraso psicomotor, tras la estimulación y apoyo adecuados, se recupera en 1 año.

\section{Evaluación y actualización del estado de inmunización}

Ausencia de certificados oficiales de vacunación -o documentos de vacunación no veraces- (en un 39-65\% de los casos, especialmente cuando los niños 
proceden de Rusia y China). En los procedentes de Europa del este, Rusia y China se ha observado que hasta en el $5 \%$ de los casos se certifica la administración de una o más vacunas antes de la fecha en que nació el menor.

Calendario incompleto o diferente al vigente en nuestro medio, ya que los países de origen frecuentemente utilizan pautas de vacunación que difieren de las nuestras. Las principales diferencias se encuentran en el tipo de vacunas utilizadas, la edad recomendada de administración, el número de dosis y el intervalo entre las mismas (al menos de 28 días).

También hay que tener presente que muchos niños adoptados, incluso con un calendario correcto, pueden no haber desarrollado una respuesta adecuada como consecuencia de la malnutrición presente en cerca del $20 \%$ de los casos.

Revisar las vacunaciones administradas en el país de origen y adecuarlas a las de la comunidad adoptiva. El objetivo es que estos niños alcancen el mismo nivel de inmunizaciones que los demás niños de nuestro medio según su edad en el menor plazo de tiempo posible. También revisar las de sus contactos domésticos.

En el caso de que no haya datos concluyentes respecto a la correlación entre los registros vacunales y el nivel de protección de los niños adoptados en el extranjero, las dos estrategias posibles son:

1. La vacunación sistemática en función de la edad y sin considerar los registros vacunales previos.

2. La realización de cribado serológico previo a la vacunación. Para ampliar información: consultar la guía extensa, disponible en www.coraenlared.org.

\section{Evaluación y seguimiento psicosocial}

Problemas de ajuste inicial:

- Problemas de sueño: dificultades para conciliar el sueño, pesadillas, insomnio, hipersomnia o sueño intranquilo.

- Problemas con la alimentación.

- Reacciones regresivas: enuresis y encopresis secundaria, episodios repentinos de llanto, miedo o ira aparentemente inmotivados y difíciles de consolar.

- Dificultades para la vinculación: ansiedad de separación, miedo o rigidez en el contacto físico, agresividad o rechazo frente a los intentos de acercamiento afectivo.

- Problemas sociales: aislamiento, miedo al contacto social con otros niños o con adultos cercanos, sociabilidad indiscriminada. 


\section{Dificultades ante las que pedir ayuda postadoptiva especializada}

- Dificultades de integración social, incluidos episodios de racismo o discriminación que el niño y la familia no saben cómo afrontar.

- Comportamientos sexuales precoces.

- Comportamientos que a la familia le resultan intolerables o imposibles de afrontar.

- Conductas que ponen en peligro su salud (autoagresiones, consumo de sustancias, deseo de hacerse daño a sí mismo, fugas) o la salud de los demás (el niño nos agrede o nos asusta, agrede gravemente a otros).

- El niño se muestra deprimido y sufre pasado un tiempo razonable de convivencia.

- El niño tiene dificultades escolares que en el colegio no saben abordar.

- La familia manifiesta que la vida de sus otros hijos está siendo afectada negativamente.
- La familia manifiesta sentir vergüenza de cómo es o cómo se comporta su hijo.

- La familia presenta serias dificultades para aceptar el crecimiento de su hijo o para separarse de él.

- La familia se manifiesta desbordada, sin fuerzas o sin ilusión para afrontar la crianza del niño.

- La familia se muestra incapaz de hablar con el niño sobre la adopción o alguno de sus aspectos.

- La familia siente al niño como un extraño o el niño no los reconoce como padres pasado un tiempo de convivencia ( +6 meses).

- La relación con el niño está generando serios desacuerdos en la pareja.

- La relación con el niño genera sentimientos de tristeza o de angustia persistentes en algún miembro de la familia que bloquean la relación. Para ampliar información consultar la guía extensa disponible en www.coraen lared.org.

\section{Bibliografía}

1. Alberola López $S$, Berástegui Pedro-Viejo $A$, De Aranzábal Agudo M, Cortés Lozano A, Fumadó Pérez V, García López -Hortelano M, García Pérez J, Hernández Merino A, Lirio Casero J,
Oliván Gonzalvo G, Parrondo Creste. Adopción Internacional. Guía para pediatras y otros profesionales sanitarios, 2008. Madrid: CORA; 2008.

2. Alberola López $S$, Berástegui Pedro-Viejo $A$, De Aranzábal Agudo $M$, Cortés Lozano A, Fumadó Pérez V, García López-Hortelano M, García Pé- 
rez J, Hernández Merino A, Lirio Casero J, Oliván Gonzalvo G, Parrondo Creste. Adopción Internacional. Guía breve para pediatras y otros profesionales sanitarios, 2008. Valladolid: CORA; 2008.

3. Alberola López $S$, Berástegui Pedro-Viejo $A$, De Aranzábal Agudo M, Cortés Lozano A, Fu- madó Pérez V, García López-Hortelano M, García Pérez J, Hernández Merino A, Lirio Casero J, Oliván Gonzalvo G, Parrondo Creste. Consens en Adopció Internacional. Guia breu per a pediatres i altres professionals sanitaris. Valladolid: CORA; 2008. 